
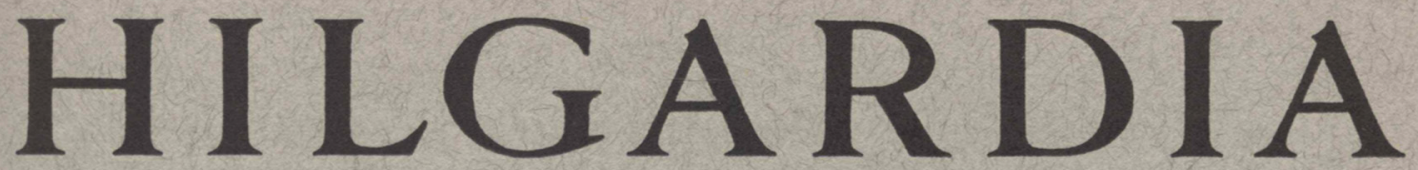

A Journal of Agricultural Science Published by the California Agricultural Experiment Station

\title{
CHROMOTROPIC ACID METHOD FOR DETERMINING 2,4-D RESIDUES IN RINSES
}

LOUIS C. ERICKSON and B. L. BRANNAMAN 
The chromotropic acid method for determining small amounts of 2,4-D was placed on a quantitative basis and used to determine the extent of contamination of various metals and glass left in contact with 2,4-D.

Aluminum, iron, and zinc retained the greatest amounts of 2,4-D, while copper, tin, and glass were more readily decontaminated.

Several prolonged rinses of water were effective in removing the salts but not the esters of 2,4-D. The esters required soaking in an organic solvent. The latter procedure would be expensive and hazardous for cleaning spray equipment.

The best way of avoiding injury to sensitive plants would be to have separate spray equipment for 2,4-D. 


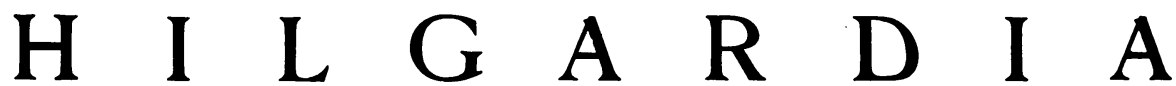

A Journal of Agricultural Science Published by

the California Agricultural Experiment Station

VoL. 23

DECEMBER, 1954

No. 7

\section{CHROMOTROPIC ACID METHOD FOR DETERMINING 2,4-D RESIDUES IN RINSES ${ }^{1,2}$}

\section{LOUIS C. ERICKSON ${ }^{3}$ and B. L. BRANNAMAN ${ }^{4}$}

SPRAY EqUIPMENT that has been used for applying 2,4-D in herbicidal concentrations has in many instances been used subsequently for other sprays, and the 2,4-D residues have seriously injured or killed sensitive plants. Efforts to remove 2,4-D residues usually have not been completely successful; thus, a potential hazard has existed whenever a contaminated sprayer has been used to spray plants sensitive to 2,4-D. Lucas and Hamner $(1947)^{5}$ reported that a 2-minute rinse with a suspension of activated charcoal removes injurious traces of 2,4-D from a sprayer.

In an attempt to gain some information on the best procedure for removing 2,4-D residues, a laboratory study was carried out in which several metals and glass were soaked in 2,4-D solutions and then rinsed by various procedures to try to remove the residues. The 2,4-D in the rinse water was determined spectrophotometrically by adapting Freed's chromotropic acid test (Freed, 1948) to a quantitative procedure.

Other quantitative adaptations of the chromotropic acid test for 2,4-D (LeTourneau and Krog, 1952; Marquardt and Luce, 1951) appear to have been worked out more or less simultaneously with the present one.

\section{PROCEDURE}

Chromotropic acid (2,7-naphthalenedisulfonic-4,5-dihydroxy acid) has been used in determining a number of substances, both inorganic (Welcher, 1947) and organic (Boos, 1948; Boyd and Logan, 1942; Bricker and Vail, 1950; Eegriwe, 1937). The use of chromotropic acid for organic analyses seems to be based in every case on its reaction with formaldehyde to form a characteristic violet color. Eegriwe (1937) first employed this reagent for detecting formaldehyde; subsequently, Boyd and Logan (1942) applied it to the indirect determination of serine by a quantitative production of formaldehyde from the latter. Similarly, Boos (1948) employed chromotropic acid

\footnotetext{
1 Received for publication March 26, 1954.

${ }^{2}$ Paper No. 809, University of California Citrus Experiment Station, Riverside, California.

${ }^{3}$ Associate Plant Physiologist in the Experiment Station, Riverside.

4 Principal Laboratory T'echnician in the Experiment Station, Riverside.

"See "Literature Cited" for citations, referred to in the text by author and date.
} 
for the indirect determination of methanol by oxidation of the latter to formaldehyde.

The absorption spectrum produced by the reactions of sulfuric, chromotropic, and 2,4-D acids in the present investigation was found to give maximum densities at 360,480 , and $580 \mathrm{~m} \mu$, using a Beckman DU spectrophotometer. These maxima coincided with those obtained when formaldehyde was used instead of 2,4-D. In developing the quantitative method with chromotropic acid, LeTourneau and Krog (1952) obtained molecular extinetion coefficients for formaldehyde, 2,4-D, and some other compounds, and found that the values for formaldehyde and 2,4-D were essentially the same. However, they considered this to be insufficient evidence to state that formaldehyde was responsible for the color produced in the 2,4-D tests.

Other evidence that formaldehyde is an intermediate product in the test was obtained in the present study. Heating a mixture of 2,4-D, chromotropic acid, and sulfuric acid to a temperature of $100^{\circ} \mathrm{C}$ did not result in the typical violet color found when the mixture was heated to higher temperatures $\left(130^{\circ}\right.$ to $150^{\circ} \mathrm{C}$ ). However, when a mixture of formaldehyde, chromotropic acid, and sulfuric acid was heated on a water bath to $100^{\circ} \mathrm{C}$ the typical violet color developed quickly. It was found that if 2,4-D and sulfuric acid were heated together in one test tube to $150^{\circ} \mathrm{C}$ and air was then bubbled through this reaction mixture and passed through a second test tube containing chromotropic and sulfuric acids heated on a water bath at $100^{\circ} \mathrm{C}$, the characteristic violet color was produced in the second test tube. Thus, the 2,4-D and sulfuric acid reacted to produce a volatile material which was carried in the stream of air to the second tube, where the chromotropic acid reacted with the volatile material to produce the violet color. That this volatile material was formaldehyde was further substantiated by Voisenet's test (Voisenet, 1905) for formaldehyde.

Freed (1948) tried to correlate halogen substitution with the tendency for color formation in the test. In the present study, color production seemed to depend on the acetic acid side chain and an ether linkage with a benzene or naphthalene ring. Thus, phenoxyacetic acid, but not phenylacetic acid, produced color with chromotropic acid. Also, 2-naphthoxyacetic acid, but not 1naphthaleneacetic acid, produced color. With regard to the side chain, 2,4-dichlorophenoxyacetic acid and 2,4,5-trichlorophenoxyacetic acid, but not 2,4dichloroanisole nor 2,4,5-trichlorophenoxypropionic acid, produced color. These data suggest that the hot sulfuric acid might have decarboxylated and split off the acetic acid side chain to produce formaldehyde.

The reactions between 2,4-D, chromotropic, and sulfuric acids were carried out in 50-ml Erlenmeyer flasks held in a wire rack which rotated in an agitated and thermostatically controlled peanut-oil bath. Other oils and glycerine were found to be objectionable because, at the temperatures used, there was enough vaporization of the bath liquid to contaminate the reaction mix. tures.

Five $\mathrm{ml}$ of standard or unknown solutions of 2,4-D were pipetted into the Erlenmeyer flasks. The water or other solvent was evaporated by gently heating and blowing compressed air over the liquid, except where the esters of 2,4-D were involved, in which case only a stream of air was used, in order to minimize loss of the ester through vaporization. 
Five $\mathrm{ml}$ of concentrated sulfuric acid containing $50 \mathrm{mg}$ of chromotropic acid were added to the 2,4-D residue in the flask as a standard procedure. The flasks were heated to $130^{\circ} \mathrm{C}$ for 20 minutes in the oil bath. A reagent blank treated in the same manner was included in each run. When the solutions were cool, the optical density was determined with a Beckman DU spectrophotometer. Although the color body absorbing radiation at $580 \mathrm{~m} \mu$ was

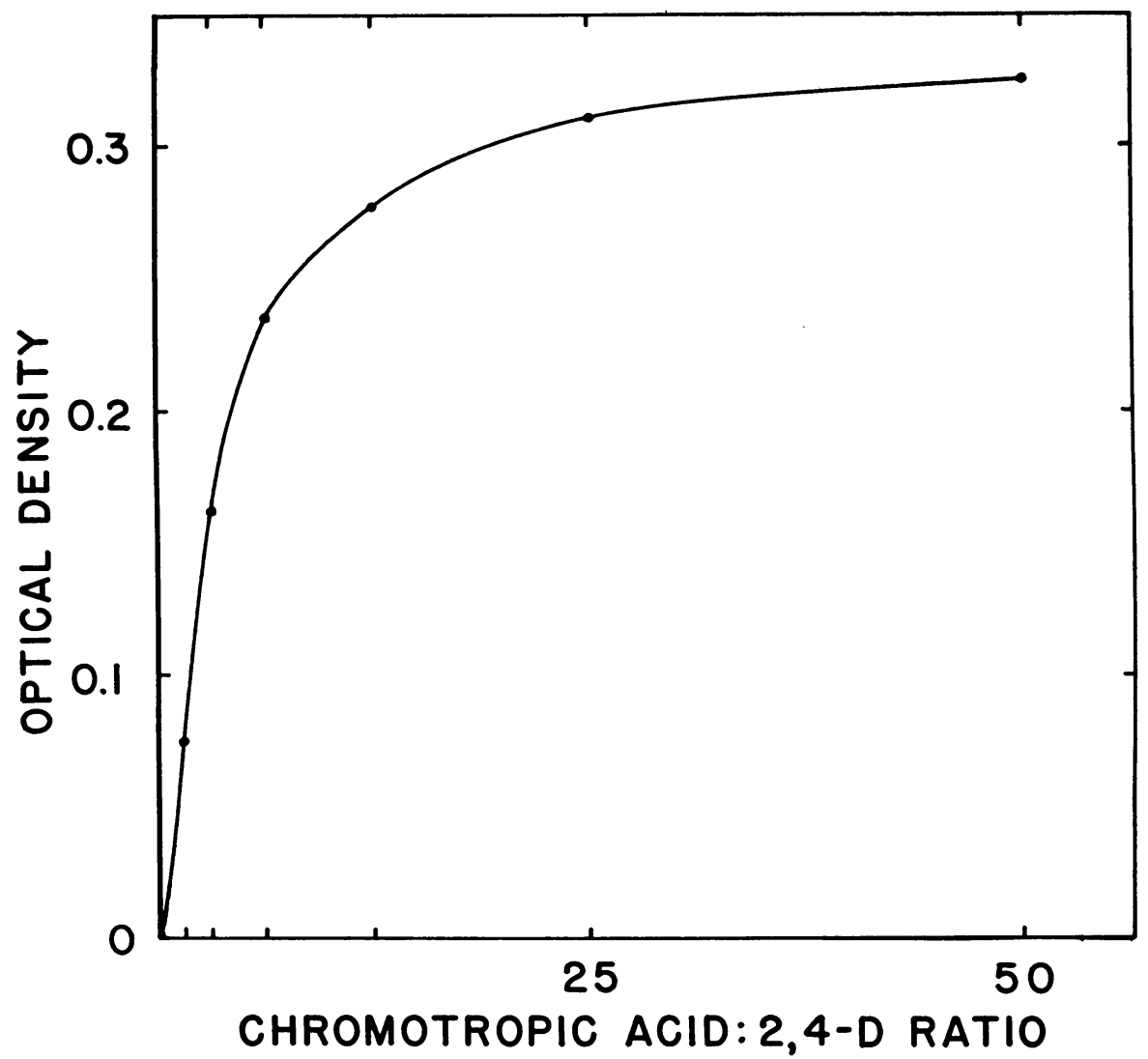

Fig. 1. Optical density at $580 \mathrm{~m} \mu$ of $2 \times 10^{-5} \mathrm{M}$ 2,4-D after reaction with different ratios of chromotropic acid in concentrated sulfuric acid at $130^{\circ} \mathrm{C}$ for 20 minutes.

stable for at least nine days, the density of each solution was determined on the same day the sample was heated. The chromotropic-sulfuric acid reagent was found to be satisfactory for several days, but because it darkened upon standing it was usually prepared as needed.

When a series of ratios of chromotropic acid to 2,4-D was tested for maximum color development, it was found that only slightly greater optical density was obtained at a ratio of $50: 1$ than at a ratio of $25: 1$, below which the density decreased rapidly (fig. 1 ).

At $100^{\circ} \mathrm{C}$ the reactions between 2,4-D, chromotropic acid, and sulfuric acid did not produce a visible color. At $120^{\circ} \mathrm{C}$ a slight violet color was ob- 
served. At $130^{\circ}$ and $150^{\circ} \mathrm{C}$ the violet color formation was rapid in appearance but required about 20 minutes to reach maximum density (fig. 2).

A dilution series made from $2 \times 10^{-4} M 2,4-\mathrm{D}$ reacted with $160 \mathrm{mg}$ chromotropic acid per $100 \mathrm{ml} \mathrm{H}_{2} \mathrm{SO}_{4}$ showed that the color produced obeyed Beer's law over a wide range of concentrations (fig. 3 ). With the volumes of materials used, the test proved to be suitable for amounts of 2,4-D ranging from 5 to $150 \mu \mathrm{g}$.

Dilution of the concentrated sulfuric acid with 2.5 to 5 per cent water did not alter the density of the color appreciably, but additional amounts of water reduced color development.

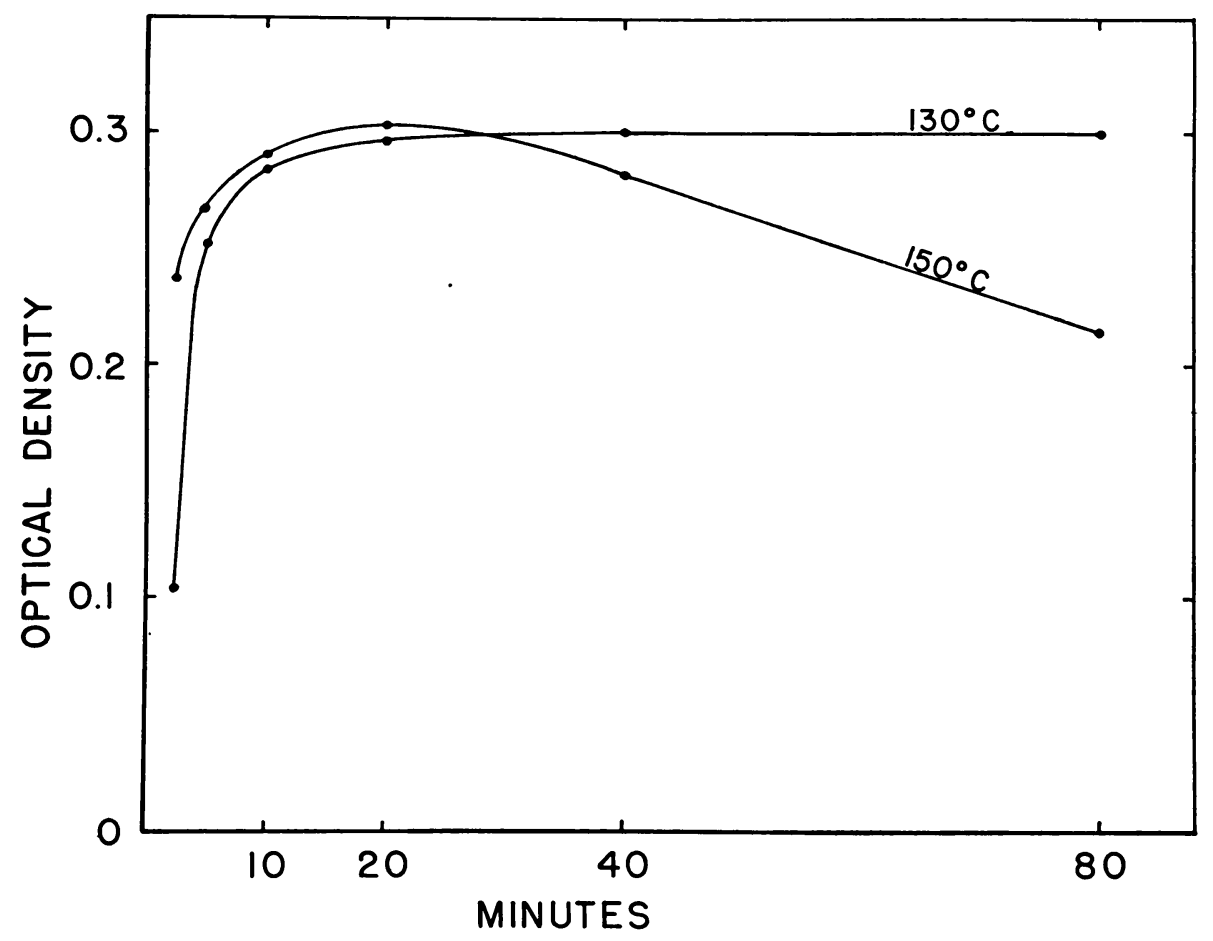

Fig. 2. Optical density at $580 \mathrm{~m} \mu$ of $2 \times 10^{-5} M 2,4-\mathrm{D}$ after reaction with $5 \times 10^{-4} M$ chromotropic acid in concentrated sulfuric acid at different temperatures and for different lengths of time.

Variability of results with the method used makes it necessary to run three or more determinations on each sample, the number depending on how accurate the estimate must be or with how small a difference statistical significance must be demonstrated. Near the minimum amount of 2,4-D determinable, triplicate determinations on each of two samples would normally establish the fact that a difference of $5 \mu \mathrm{g}(1 \mathrm{mg}$ per liter) between the samples was significant at the 5 per cent level; near the maximum amount determinable, triplicate determinations would similarly establish the fact that a difference of $25 \mu \mathrm{g}$ ( $5 \mathrm{mg}$ per liter) between the samples was significant at the 5 per cent level (Snedecor, 1940). 


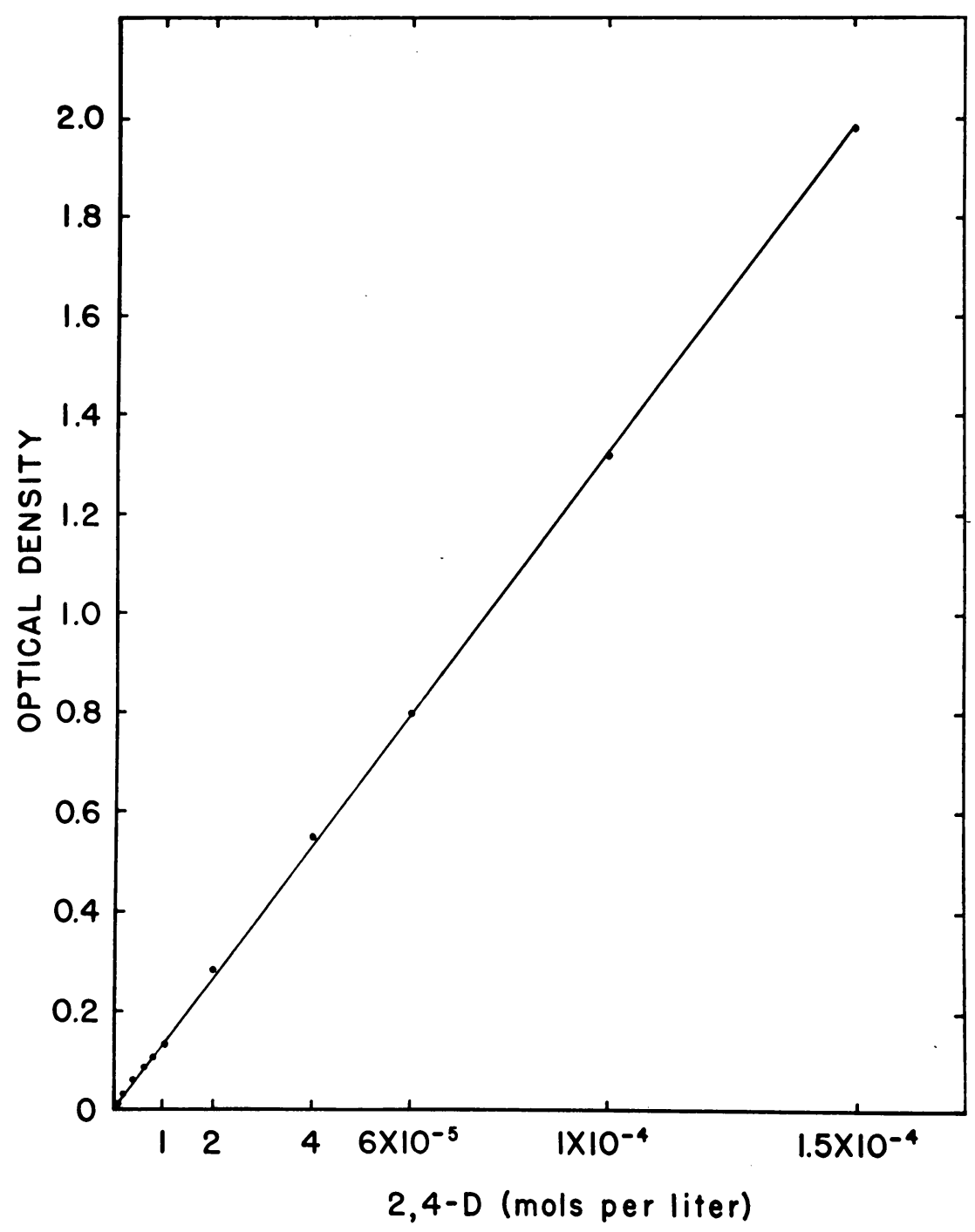

Fig. 3. Optical density at $580 \mathrm{~m} \mu$ of a dilution series of 2,4-D made after reaction with chromotropic acid in concentrated sulfuric acid heated to $130^{\circ} \mathrm{C}$ for 20 minutes.

\section{RESULTS}

Water Rinses. An aqueous solution of sodium 2,4-dichlorophenoxyacetate was prepared to contain 0.1 per cent of the acid equivalent. Approximately $50 \mathrm{ml}$ of this solution was poured into $50-\mathrm{ml}$ beakers containing pieces of zine (galvanized iron), copper, tin, iron, aluminum, or glass. Each piece of metal was about $3.2 \mathrm{~cm}$ square; metal of this size was large enough not to lie flat on the bottom of the beaker. Controls were soaked in distilled water. After standing for approximately 24 hours, the $2,4-\mathrm{D}$ solution or water (in the 
controls) was poured from the beakers and discarded. Each beaker was then filled with $50 \mathrm{ml}$ of water, which was immediately poured off and saved for analysis. Four such rapid rinses were made; succeeding rinses were allowed to remain in the beakers for 24 hours each.

Five-ml aliquots of the rinses were tested in duplicate or triplicate for 2,4-D by the method described above. The water in which the controls were

TABLE 1

DETERMINATION OF 2,4-D IN RINSE WATER FROM VARIOUS MATERIALS SOAKED IN 0.1 PER CENT SODIUM 2,4-DICHLOROPHENOXYACETATE FOR APPROXIMATELY 24 HOURS

\begin{tabular}{|c|c|c|c|c|c|c|c|c|}
\hline \multirow{3}{*}{ Material } & \multicolumn{8}{|c|}{ Milligrams 2,4-D acid equivalent per liter } \\
\hline & \multicolumn{4}{|c|}{ Rapid rinse } & \multicolumn{4}{|c|}{ 24-hour rinse } \\
\hline & 1 & 2 & 3 & 4 & 5 & 6 & 7 & 8 \\
\hline Copper... & $\begin{array}{l}8.0 \\
8.4\end{array}$ & $\begin{array}{l}0 \\
0\end{array}$ & $\begin{array}{l}0 \\
0\end{array}$ & $\begin{array}{l}0 \\
0\end{array}$ & $\begin{array}{l}0 \\
0.3\end{array}$ & $\begin{array}{l}0 \\
0\end{array}$ & $\begin{array}{l}0 \\
0\end{array}$ & $\begin{array}{l}0 \\
0\end{array}$ \\
\hline Mean. & 8.2 & 0 & 0 & 0 & 0.15 & 0 & 0 & 0 \\
\hline Iron....... & $\begin{array}{l}4.6 \\
4.8 \\
4.8\end{array}$ & $\begin{array}{l}0 \\
0 \\
0\end{array}$ & $\begin{array}{l}0.3 \\
0.4 \\
0.2\end{array}$ & $\begin{array}{l}0 \\
0 \\
0\end{array}$ & $\begin{array}{l}2.7 \\
2.3 \\
1.6\end{array}$ & $\begin{array}{l}\ldots \\
\ldots \\
.\end{array}$ & $\begin{array}{l}\cdots \\
\cdots \\
\cdots\end{array}$ & $\begin{array}{l}. . \\
. . \\
.\end{array}$ \\
\hline Mean & 4.73 & 0 & 0.3 & 0 & 2.2 & 0 & 0 & 0 \\
\hline $\operatorname{Tin} . .$. & $\begin{array}{l}11.4 \\
10.0\end{array}$ & $\begin{array}{l}0 \\
0\end{array}$ & $\begin{array}{l}0 \\
0\end{array}$ & $\begin{array}{l}0 \\
0\end{array}$ & $\begin{array}{l}0 \\
0\end{array}$ & $\begin{array}{l}0 \\
0\end{array}$ & $\begin{array}{l}\cdots \\
\ldots\end{array}$ & $\begin{array}{l}. . \\
. .\end{array}$ \\
\hline Mean. & 10.7 & 0 & 0 & 0 & 0 & 0 & . & . \\
\hline Zinc... & $\begin{array}{l}8.7 \\
8.4\end{array}$ & $\begin{array}{l}0.4 \\
0.2\end{array}$ & $\begin{array}{l}0 \\
0\end{array}$ & $\begin{array}{l}0 \\
0\end{array}$ & $\begin{array}{l}7.9 \\
7.6\end{array}$ & $\begin{array}{l}1.40 \\
1.00\end{array}$ & $\begin{array}{l}0.4 \\
1.0\end{array}$ & $\begin{array}{l}0.6 \\
0.5\end{array}$ \\
\hline Mean. & 8.55 & 0.3 & 0 & 0 & 7.75 & 1.20 & 0.7 & 0.55 \\
\hline Glass. & $\begin{array}{l}6.2 \\
6.8\end{array}$ & $\begin{array}{l}0.3 \\
0.3\end{array}$ & $\begin{array}{l}0 \\
0\end{array}$ & $\begin{array}{l}0.1 \\
. .\end{array}$ & $\begin{array}{l}0.15 \\
0.30\end{array}$ & $\begin{array}{l}0 \\
0\end{array}$ & $\begin{array}{l}0.2 \\
0.4\end{array}$ & $\begin{array}{l}0 \\
0\end{array}$ \\
\hline Mean. & 6.5 & 0.3 & 0 & 0.1 & 0.22 & 0 & 0.3 & 0 \\
\hline
\end{tabular}

rinsed was used to prepare the reagent blanks. The rinse water from the containers that held the iron had to be treated for removal of the iron before determination of the 2,4-D content. Iron was removed by the following method (Treadwell, 1942): Three drops of $\mathrm{HCl}$ were added to the $50 \mathrm{ml}$ of rinse water, which was then heated to boiling; four drops of $\mathrm{NH}_{4} \mathrm{OH}$ were added, and the mixture was then boiled for two minutes. Cold water was added to obtain the original weight of solution before filtering. Five-ml aliquots of the cooled filtrate were then taken for analysis.

Nearly all of the 2,4-D appeared to be rinsed from the metals and glass by the first of the four rapid rinses (table 1). However, a subsequent rinse water which stayed in the beakers for 24 hours showed that varying amounts of 
adsorbed 2,4-D were slowly released from the materials. The tin appeared to be free from contamination. The copper and glass retained a trace of 2,4-D. The iron and zine showed appreciable residual contamination. Four 24-hour rinses were made of the zine with the result that a decreasing but readily detectable amount of 2,4-D was found in each rinse water.

The rinsing of the aluminum differed from that of the other materials in that after the first rapid rinse, the water was allowed to remain in contact

TAIBLE 2

EFFECT OF DURATION OF WATER RINSE ON AMOUNT OF 2,4-D RESIDUE FROM ALUMINUM PREVIOUSLY SOAKED IN SODIUM 2,4-DICHLOROPHENOXYACETATE FOR APPROXIMATELY 24 HOURS

\begin{tabular}{|c|c|c|c|c|}
\hline \multicolumn{2}{|r|}{ Water rinse } & \multicolumn{3}{|c|}{ Milligrams 2,4-D per liter } \\
\hline No. & Duration & Sample 1 & Sample 2 & Mean \\
\hline 1 & $\operatorname{Rapid} \ldots \ldots \ldots \ldots \ldots \ldots \ldots \ldots \ldots \ldots$ & 7.9 & 7.5 & 7.7 \\
\hline 2 & $\ldots \ldots \ldots \ldots \ldots$ & 1.4 & 1.0 & 1.2 \\
\hline 3 & 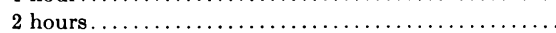 & 0.4 & 0.4 & 0.4 \\
\hline 4 & 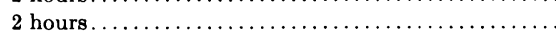 & 0.0 & 0.0 & 0.0 \\
\hline 5 & 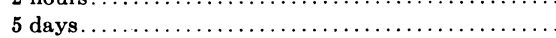 & 2.4 & 3.0 & 2.7 \\
\hline 6 & 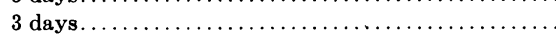 & 0.6 & 0.6 & 0.6 \\
\hline
\end{tabular}

TABLE 3

EFFECT OF AMMONIA WATER RINSE ON AMOUNT OF 2,4-D RESIDUE FROM ZINC PREVIOUSLY SOAKED FOR 24 HOURS IN 0.1 PER CENT 2,4-D AS TRIETHANOLAMMONIUM DICHLOROPHENOXYACETATE

\begin{tabular}{|c|c|c|c|c|c|}
\hline \multirow{2}{*}{$\begin{array}{l}\text { Preliminary rapid rinses } \\
(4)\end{array}$} & \multirow{2}{*}{$\begin{array}{c}\text { Fifth rinse } \\
\text { (4 days' duration) }\end{array}$} & \multicolumn{4}{|c|}{ Milligrams 2,4-D per liter } \\
\hline & & Sample 1 & Sample 2 & Sample 3 & Mean \\
\hline Water... & 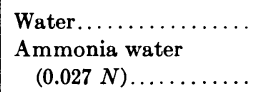 & $\begin{array}{l}2.3 \\
9.5\end{array}$ & $\begin{array}{l}2.3 \\
7.7\end{array}$ & $\begin{array}{l}2.8 \\
8.2\end{array}$ & $\begin{array}{l}2.5 \\
8.5\end{array}$ \\
\hline $\begin{array}{l}\text { Ammonia water } \\
\quad(0.027 N) \ldots \ldots\end{array}$ & $\begin{array}{l}\text { Water................ } \\
\text { Ammonia water } \\
\quad(0.027 N) \ldots \ldots \ldots \ldots\end{array}$ & $\begin{array}{l}3.2 \\
8.9\end{array}$ & $\begin{array}{l}3.3 \\
8.7\end{array}$ & $\begin{array}{l}2.4 \\
7.8\end{array}$ & 3.0 \\
\hline
\end{tabular}

with the metal for one or two hours for the second, third, and fourth rinses (table 2). Each of the first three rinses showed a decreasing amount of 2,4-D. No 2,4-D was found in the fourth rinse, but the fifth rinse, which remained in contact with the metal for five days, again showed appreciable contamination. The sixth rinse, which remained in contact with the metal for three days, still showed 2,4-D contamination, although at this time the concentration was less than $1 \mathrm{mg}$ per liter.

A comparison of bright and tarnished zinc was made to determine the relative contamination of the metal in these states. After soaking the metal in 0.1 per cent 2,4-D as sodium 2,4-dichlorophenoxyacetate for 24 hours and rinsing rapidly four times, the fifth rinse water was allowed to remain in contact with the metal for 24 hours. An analysis of the fifth rinse water 
showed that contamination of the rinse water from the bright zinc was $1.5 \mathrm{mg}$ 2,4-D per liter, whereas that from the tarnished zinc was $13.0 \mathrm{mg}$ per liter.

Ammonia Water Rinses. Instructions on packages of 2,4-D have sometimes stated that spray tanks should be washed with ammonia water or other alkaline material after being used for 2,4-D. A test for the effectiveness of this procedure was made using zinc as the test metal. After a soaking period of 24 hours in 0.1 per cent $2,4-\mathrm{D}$ as triethanolammonium dichlorophenoxyacetate,

TABLE 4

EFFECT OF WATER AND ACETONE RINSES ON AMOUNT OF 2,4-D ESTER IN RESIDUE FROM MATERIALS PREVIOUSLY SOAKED IN 0.1 PER CENT BUTYL, 2,4-DICHLOROPHENOXYACETATE FOR, 24 HOURS

\begin{tabular}{|c|c|c|c|c|c|c|c|}
\hline \multirow{2}{*}{ Material } & \multicolumn{3}{|c|}{ Rinse* } & \multicolumn{4}{|c|}{ Milligrams 2,4-D per liter } \\
\hline & No. & Duration & Solvent & Sample 1 & Sample 2 & Sample 3 & Mean \\
\hline \multicolumn{8}{|l|}{ Glass: } \\
\hline \multirow{3}{*}{ Group 1} & 4 & Rapid & Water & 0.9 & 1.4 & 1.1 & 1.1 \\
\hline & 5 & 24 hours & Water & 0.7 & 1.0 & 1.4 & 1.0 \\
\hline & 6 & 5 days & Acetone & 40.3 & 39.6 & 41.2 & 40.4 \\
\hline \multirow[t]{3}{*}{ Group 2 . } & 4 & Rapid & Acetone & 0.2 & 0.5 & 0.4 & 0.4 \\
\hline & 5 & 24 hours & Acetone & 0.2 & 0.0 & 0.1 & 0.1 \\
\hline & 6 & 5 days & Acetone & 0.5 & 0.1 & 0.1 & 0.2 \\
\hline \multicolumn{8}{|l|}{ Copper: } \\
\hline \multirow[t]{3}{*}{ Group 1.. } & 4 & Rapid & Water & 2.5 & 1.7 & 1.3 & 1.8 \\
\hline & 5 & 24 hours & Water & 1.3 & 2.0 & 1.3 & 1.5 \\
\hline & 6 & 5 days & Acetone & 27.0 & 20.6 & 29.2 & 25.6 \\
\hline \multirow[t]{3}{*}{ Group 2 . } & 4 & Rapid & Acetone & 0.0 & 0.0 & 0.0 & 0.0 \\
\hline & 5 & 24 hours & Acetone & 1.4 & 0.9 & 1.1 & 1.1 \\
\hline & 6 & 5 days & Acetone & 0.4 & 0.3 & 0.5 & 0.4 \\
\hline \multicolumn{8}{|l|}{ Zinc: } \\
\hline \multirow[t]{3}{*}{ Group 1} & 4 & Rapid & Water & 0.0 & 1.0 & 1.0 & 0.7 \\
\hline & 5 & 24 hours & Water & 4.9 & 5.6 & 6.6 & 5.7 \\
\hline & 6 & 5 days & Acetone & 26.8 & 14.0 & 24.1 & 21.6 \\
\hline \multirow[t]{3}{*}{ Group 2 . } & 4 & Rapid & Acetone & 1.1 & 0.6 & 1.0 & 0.9 \\
\hline & 5 & 24 hours & Acetone & 3.1 & 3.3 & 3.8 & 3.4 \\
\hline & 6 & 5 days & Acetone & 3.0 & .3 .6 & 3.8 & 3.5 \\
\hline
\end{tabular}

* The first three rinses of each group of materials were the same as rinse No. 4 for that group.

the zine was rinsed rapidly four times in water or ammonia water (household ammonia diluted $1: 100$, making $0.027 \mathrm{~N}$ ). For the fifth rinse the metal was soaked for four days in either water or ammonia water in all combinations used with the rapid rinses (table 3 ). The results showed that the rapid rinses in ammonia water did not remove the adsorbed 2,4-D. Subsequent soaking in either water or ammonia water released additional 2,4-D from the metal, but the use of ammonia for the prolonged soaking appeared to facilitate the liberation of the adsorbed 2,4-D.

Removal of 2,4-D Esters. A test for the removal of butyl 2,4-dichlorophenoxyacetate from glass, copper, and zine was made in the same manner as 
the previous tests, except that acetone was also tried as a solvent. Acetone is a good solvent for the esters of 2,4-D and has the advantage of being miscible with water. It was necessary to redistill the acetone, however, before using it in the tests, because impurities interfered with the 2,4-D determinations.

After soaking one set of materials in 0.1 per cent 2,4-D as the butyl ester, four rapid water rinses were made. The fifth water rinse was in contact with the materials for 24 hours. The sixth rinse was made with acetone, which was in contact with the materials for five days. Another set of materials was rinsed only with acetone.

The amounts of 2,4-D found in the rinses are shown in table 4. Water was very ineffective in removing the ester from any of the materials. Although the amount of 2,4-D in the rinse water was low, the final soaking in acetone showed that a great amount of ester was still present. Even six rinses with acetone, of which two were long periods of soaking, failed to remove all the 2,4-D ester.

\section{DISCUSSION}

Determination of 2,4-D residues with chromotropic acid was found to be readily possible under the conditions of the present studies, where interfering substances could be avoided. Similarly, satisfactory results were obtained with the method in analyzing for spray deposits, where the 2,4-D could be caught in petri dishes (Stewart, Gammon, and Hield, 1952). However, when chromotropic acid is dissolved in concentrated sulfuric acid the possibility of other organic substances interfering is very great.

The extinction coefficients determined by LeTourneau and Krog (1952), together with the evidence of formaldehyde production presented in this paper, indicates that the basis for the color produced by 2,4-D and chromotropic acid is the same as that first described for formaldehyde and chromotropic acid by Eegriwe (1937).

Results of the residue studies show that 2,4-D adsorption may be a serious problem in the cleaning of spray equipment for subsequent use on plants sensitive to 2,4-D. Several rapid rinses of water or ammonia water were ineffective in removing the residual 2,4-D present in salt forms. The best procedure for removing 2,4-D was to soak contaminated materials in water for long periods, with changes every few hours or daily.

Water was not satisfactory for the removal of the ester form of 2,4-D. Even though acetone is an excellent solvent for esters of 2,4-D, it was found to be incapable of completely removing the 2,4-D ester with rapid rinsing. Several changes of an organic solvent in spray equipment would be impracticable from the cost standpoint, and would also be somewhat hazardous from the standpoint of safety.

Because kerosene is a good solvent for 2,4-D esters and is readily available, a small amount of it emulsified with a detergent should make a suitable rinsing material for the bulk of the loose 2,4-D-ester residue in spray equipment. Complete removal of the 2,4-D ester does not appear to be readily possible.

The practical solution to the problem of 2,4-D residues in spray equipment would be to maintain separate equipment for 2,4-D or for plants extremely sensitive to 2,4-D. 


\section{SUMMARY}

1. A quantitative adaptation for the determination of small amounts of 2,4-D with chromotropic acid is presented.

2. Evidence is presented that the basis for the chromotropic acid test is the formation of formaldehyde from the 2,4-D.

3 . Analyses of rinsing solvents showed that adsorbed 2,4-D was slowly released from metals.

4. Zine, iron, and aluminum were found to be the most difficult to clean after contamination with 2,4-D. Tin, copper, and glass were most readily decontaminated.

5 . The ester form of 2,4-D was not readily removed from metals, even with several prolonged rinses of acetone.

\section{ACKNOWLEDGMENT}

The authors are grateful to Dr. Francis A. Gunther for suggestions.

\section{LITERATURE CITED}

Boos, R. N.

1948. Quantitative colorimetric microdetermination of methanol with chromotropic acid reagent. Analyt. Chem. $20: 964-65$.

Boyd, M. J., and M. A. LogAN

1942. Colorimetric determination of serine. Jour. Biol. Chem. 146:279-87.

Bricker, C. E., and W. A. VAIL

1950. Microdetermination of formaldehyde with chromotropic acid. Analyt. Chem. 22: 720-22.

EEGRIWE, E.

1937. Reaktionen und Reagenzien zum nachweis organischer Verbindungen. Ztschr. $f$. Analyt. Chem. $110: 22-25$.

Freed, V. H.

1948. Qualitative reaction for 2,4-dichlorophenoxyacetic acid. Science 107:98-99.

LeTourneau, Duane, and Norman KroG

1952. The use of chromotropic acid for the quantitative determination of 2,4-dichlorophenoxyacetic acid. Plant Physiol. $27: 822-27$.

LUCAS, E. H., and C. L. HAMNER

1947. Inactivation of 2,4-D by adsorption on charcoal. Science $105: 340$.

MARQUARDT, R. P., and E. N. LUCE

1951. Determination of small amounts of 2,4-dichlorophenoxyacetic acid in milk. Analyt. Chem. $23: 1484-86$.

SNEDECOR, GEORGE W.

1940. Statistical methods. 3d ed., chap. 4. Collegiate Press, Inc., Ames, Iowa.

Stewart, Wm. S., Cyril Gammon, and H. Z. Hield

1952. Deposit of 2,4-D and kill of wild grapevines by helicopter spray application. Amer. Jour. Bot. $39: 1-5$.

Treadwell, F. P.

1942. Analytical Chemistry. 9th ed., vol. 2, chap. 3 (revised by W. T. Hall). John Wiley \& Sons, New York.

VOISENET, M. E.

1905. Sur une réaction tres sensible de la formaldéhyde et des composés oxygénés de l'azote et qui est aussi une réaction de coloration des matiéres albuminoídes. Soc. Chim. de France Bul. 33:1198-1214. (Cf. Merck Index, 5th ed., 1940, p. 952).

Welcher, Frank J.

1947. Organic analytical reagents. Vol. 1, chap. 12. C. Van Nostrand Company, Inc., New York. 
The journal Hilgardia is published at irregular intervals, in volumes of about 600 pages. The number of issues per volume varies.

Subscriptions are not sold. The periodical is sent as published only to libraries, or to institutions in foreign countries having publications to offer in exchange.

You may obtain a single copy of any issue free, as long as the supply lasts; please request by volume and issue number from:
Agricultural Publications
Room 22, Giannini Hall
University of California
Berkeley 4, California

The limit to nonresidents of California is 10 separate issues on a single order. A list of the issues still available will be sent on request. 